\title{
Precursor Amino Acids Inhibit Polymyxin E Biosynthesis in Paenibacillus polymyxa, Probably by Affecting the Expression of Polymyxin E Biosynthesis-Associated Genes
}

\author{
Zhiliang Yu, Chenglin Guo, and Juanping Qiu \\ College of Biological and Environmental Engineering, Zhejiang University of Technology, Hangzhou 310014, China \\ Correspondence should be addressed to Zhiliang Yu; zlyu@zjut.edu.cn and Juanping Qiu; qiujping@zjut.edu.cn
}

Received 12 December 2014; Revised 4 May 2015; Accepted 7 May 2015

Academic Editor: Paul M. Tulkens

Copyright (C) 2015 Zhiliang Yu et al. This is an open access article distributed under the Creative Commons Attribution License, which permits unrestricted use, distribution, and reproduction in any medium, provided the original work is properly cited.

\begin{abstract}
Polymyxin E belongs to cationic polypeptide antibiotic bearing four types of direct precursor amino acids including L-2,4diaminobutyric acid (L-Dab), L-Leu, D-Leu, and L-Thr. The objective of this study is to evaluate the effect of addition of precursor amino acids during fermentation on polymyxin E biosynthesis in Paenibacillus polymyxa. The results showed that, after $35 \mathrm{~h}$ fermentation, addition of direct precursor amino acids to certain concentration significantly inhibited polymyxin E production and affected the expression of genes involved in its biosynthesis. L-Dab repressed the expression of polymyxin synthetase genes $p m x A$ and $p m x E$, as well as 2,4-diaminobutyrate aminotransferase gene ectB; both L-Leu and D-Leu repressed the pmxA expression. In addition, $\mathrm{L}-\mathrm{Thr}$ affected the expression of not only $p m x A$, but also regulatory genes $s p o 0 A$ and $a b r B$. As L-Dab precursor, L-Asp repressed the expression of $e c t B, p m x A$, and $p m x E$. Moreover, it affected the expression of $s p o 0 A$ and $a b r B$. In contrast, L-Phe, a nonprecursor amino acid, had no obvious effect on polymyxin E biosynthesis and those biosynthesis-related genes expression. Taken together, our data demonstrated that addition of precursor amino acids during fermentation will inhibit polymyxin $\mathrm{E}$ production probably by affecting the expression of its biosynthesis-related genes.
\end{abstract}

\section{Introduction}

Polymyxin E is biosynthesized in Paenibacillus polymyxa [1]. It has been used as an important therapy for infection caused by Gram-negative pathogens since 1959. However, its clinical use was soon limited due to its adverse nephrotoxicity and neurotoxicity [2]. Recently, multidrug resistance in pathogens to almost all currently available antibiotics is becoming a big threat for human health, leaving very limited choices for clinical therapy [3-5]. In many cases, polymyxin $\mathrm{E}$ is considered as one of the last-line available options for treatment of multidrug-resistant bacteria $[6,7]$.

The basic structure of polymyxin $\mathrm{E}$ is a cyclic heptapeptide with a tripeptide side chain acylated by a fatty acid at the amino terminus $[8,9]$. It is biosynthesized by a multienzyme nonribosomal peptide synthetase system (NRPS) [1, 10-12]. A gene cluster for its biosynthesis has been determined to have five open reading frames, $p m x A$, $p m x B, p m x E$, $p m x C$, and $p m x D$, encoding three polymyxin synthetases
PmxA, PmxB, and PmxE, and two membrane transporters PmxC and PmxD, respectively [13-16]. PmxA comprises four modules whose amino acid substrates are D-Leu, LLeu, L-2,4-diaminobutyric acid (L-Dab), and another L-Dab, while PmxB composes only one module with L-Thr as its amino acid substrate. PmxB is also responsible for synthesis termination. PmxE is another synthetase with five modules whose amino acid substrates are L-Dab, L-Thr, L-Dab, LDab, and L-Dab. In total, polymyxin E consists of ten orderly assembled amino acid residues or precursor amino acids [17]. Among them, six are L-Dabs which are biosynthesized by 2,4diaminobutyrate aminotransferase (EctB) encoded by ectB [18]. It has been reported that addition of L-Dab to medium at the beginning of fermentation can stimulate polymyxin E production [19]. Moreover, addition of L-aspartic acid (LAsp), Dab precursor, to medium in the presence of $\mathrm{PO}_{4}{ }^{3-}$ can also stimulate $P$. polymyxa to produce polymyxin E. In contrast, addition of L-Ile and L-Val gave suppression and the amino acids L-Thr and L-Leu gave no change in 


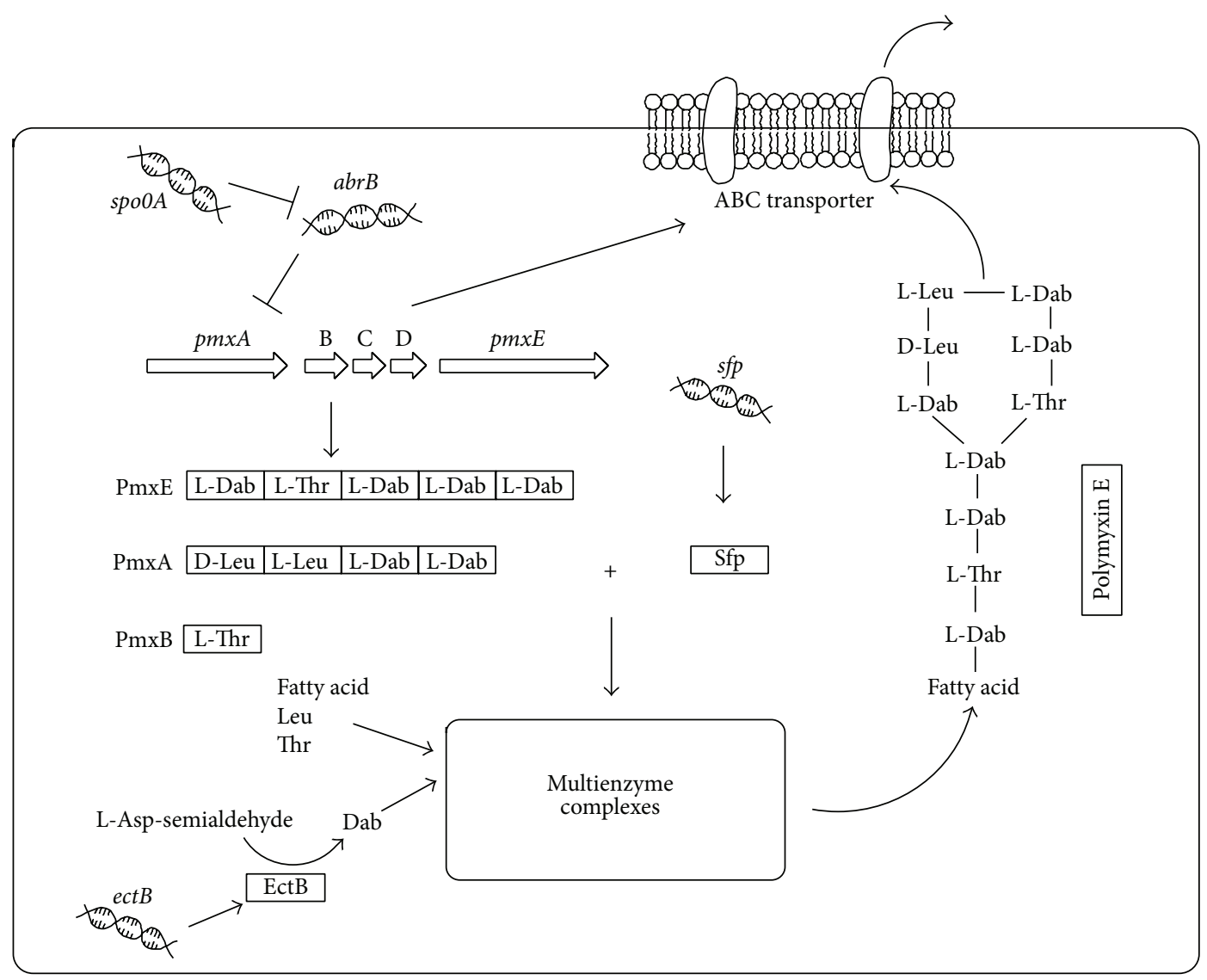

FIGURE 1: Relationships among the polymyxin E biosynthesis-related genes [13-17, 27]. Polymyxin E is biosynthesized by a multienzyme system named NRPS, which is comprised of three synthetases PmxA, PmxB, and PmxE encoded by $p m x A$, $p m x B$, and $p m x E$, respectively. PmxA comprises four modules whose amino acid substrates are D-Leu, L-Leu, L-Dab, and L-Dab. PmxB composes only one module with LThr as its amino acid substrate. PmxE has five modules whose amino acid substrates are L-Dab, L-Thr, L-Dab, L-Dab, and L-Dab. Based on the polymyxin E structure, the order of modules for amino acid assembly during polymyxin E synthesis is PmxE-PmxA-PmxB, which is consistent with the order of ten amino acid groups on polymyxin E molecule. The multienzyme system is probed and activated by phosphopantetheinyl transferase (Sfp) encoded by $s f p$. The $p m x A$ expression is negatively regulated by a DNA-binding protein, AbrB encoded by $a b r B$. The $a b r B$ expression is negatively regulated by another DNA-binding protein, Spo0A encoded by spo0A. Polymyxin E is secreted by ABC transporters PmxC and PmxD encoded by $p m x C$ and $p m x D$, respectively. Dab is synthesized from L-asp-semialdehyde (L-Asp) by EctB which is encoded by ectB. Fatty acid: 6-methyloctanoic acid or isooctanoic acid; Thr: threonine; Phe: phenylalanine; Leu: leucine; and Dab: $\alpha, \gamma$-diaminobutyric acid.

polymyxin production [19]. To date, there is no report on the molecular mechanism in affecting polymyxin E production upon addition of precursor amino acids during fermentation.

It has been reported that polymyxin $\mathrm{E}$ biosynthesis is negatively regulated by $\mathrm{AbrB}$, a DNA-binding protein, by directly binding to the upstream region of pmxA [18]. $\mathrm{AbrB}$ itself is an unstable protein and its gene expression is negatively regulated by Spo0A, another DNA-binding protein encoded by spo0A [20-23]. Besides these two regulation proteins, phosphopantetheinyl transferase (Sfp) encoded by $s f p$ was found to be important in priming and activating NRPS [24-26]. All these genes together with the ones in gene cluster are believed to be important for polymyxin $\mathrm{E}$ biosynthesis and their relationships are outlined in Figure 1 $[13-17,27]$.

In this study, we aim to investigate the effect of precursor amino acids added during fermentation on polymyxin E production in P. polymyxa. We found that addition of precursor amino acids will suppress polymyxin E production probably by affecting the expression of polymyxin $\mathrm{E}$ biosynthesisrelated genes. We believe that this study would be useful for understanding the regulation mechanism underlying polymyxin E biosynthesis during fermentation.

\section{Materials and Methods}

2.1. Strain and Culture Conditions. As the producer of polymyxin E, P. polymyxa used in this study was supplied by Zhejiang Qianjiang Biochemical Co., Ltd., China, and frozen at $-80^{\circ} \mathrm{C}$ in our lab at Zhejiang University of Technology, China. Unless otherwise specified, P. polymyxa was firstly cultivated on agar plate $(10 \mathrm{~g} / \mathrm{L}$ of beef extract, $15 \mathrm{~g} / \mathrm{L}$ of peptone, $10 \mathrm{~g} / \mathrm{L}$ of glucose, $2 \mathrm{~g} / \mathrm{L}$ of yeast extract, $3 \mathrm{~g} / \mathrm{L}$ of $\mathrm{NaCl}$, $0.1 \mathrm{~g} / \mathrm{L}$ of $\mathrm{FeSO}_{4} \cdot 7 \mathrm{H}_{2} \mathrm{O}$, and $20 \mathrm{~g} / \mathrm{L}$ of agar) at $30^{\circ} \mathrm{C}$ for $2 \mathrm{~d}$. Then, a ring of $P$. polymyxa was transferred to $50 \mathrm{~mL}$ of seed medium $(30 \mathrm{~g} / \mathrm{L}$ of soybean meal, $5 \mathrm{~g} / \mathrm{L}$ of soybean oil, $0.1 \mathrm{~g} / \mathrm{L}$ 
TABLE 1: Sequences of primer pairs for PCR amplification of genes involved in polymyxin E biosynthesis.

\begin{tabular}{|c|c|c|c|}
\hline \multirow{2}{*}{ Genes } & \multicolumn{2}{|c|}{ Nucleotide sequences $\left(5^{\prime}-3^{\prime}\right)$} & \multirow{2}{*}{ Product sizes (bp) } \\
\hline & Forward primers & Reverse primers & \\
\hline$p m x A$ & CCGCCCATTATGACAACCGT & GCTGGCGAATTGAACGATCC & 1238 \\
\hline$p m x B$ & ATGAAATCTTTGTTTGAAAA & CCAGGACGTACACCCTCAAC & 1878 \\
\hline $\operatorname{pmx} C$ & AAAGGCTGGATGATCGTCGG & AGAAAGCCGGTGGGCAATAA & 1547 \\
\hline$p m x D$ & ATGAAAAAGGGCGGATGGCT & CTAGCCGTACAGCCGGGCGT & 1734 \\
\hline$p m x E$ & GCAAAATCCAACGCAGTGGT & ACGTTGAGAATGCGGTGTCT & 1135 \\
\hline spooA & ATGAAAATATACGCGATTGA & TTACGCCTGTGTTGCCACTT & 699 \\
\hline$a b r B$ & TCAGTTTGTCACAGGTGTTG & ATGATGAAATCCACTGGATA & 255 \\
\hline$e c t B$ & ATGAACACATTCGAAACACT & TACGCCCAGCACGTTCAATA & 1145 \\
\hline$s f p$ & TTGCAAAAAATTGAGGTATT & TCAGGACACCTTATTCTCAA & 804 \\
\hline
\end{tabular}

of $\mathrm{FeSO}_{4} \cdot 7 \mathrm{H}_{2} \mathrm{O}, 15 \mathrm{~g} / \mathrm{L}\left(\mathrm{NH}_{4}\right)_{2} \mathrm{SO}_{4}, 0.77 \mathrm{~g} / \mathrm{L}$ of $\mathrm{KH}_{2} \mathrm{PO}_{4}$, $0.7 \mathrm{~g} / \mathrm{L}$ of $\mathrm{CaCO}_{3}$, and $10 \mathrm{~g} / \mathrm{L}$ of glucose) in $250 \mathrm{~mL}$ flask for incubation at $30^{\circ} \mathrm{C}$ for $24 \mathrm{~h}$ with shaking at $200 \mathrm{rpm}$. Next, $5 \mathrm{~mL}$ of cell culture was transferred to $50 \mathrm{~mL}$ of fermentation medium $(23.9 \mathrm{~g} / \mathrm{L}$ of soybean meal, $21.1 \mathrm{~g} / \mathrm{L}$ of soybean meal powder, $10 \mathrm{~g} / \mathrm{L}$ of soybean oil, $0.1 \mathrm{~g} / \mathrm{L}$ of $\mathrm{FeSO}_{4} \cdot 7 \mathrm{H}_{2} \mathrm{O}, 25 \mathrm{~g} / \mathrm{L}$ $\left(\mathrm{NH}_{4}\right)_{2} \mathrm{SO}_{4}, 0.77 \mathrm{~g} / \mathrm{L}$ of $\mathrm{KH}_{2} \mathrm{PO}_{4}, 1 \mathrm{~g} / \mathrm{L}$ of $\mathrm{CaCO}_{3}$, and $25 \mathrm{~g} / \mathrm{L}$ of glucose) in $250 \mathrm{~mL}$ flask at $30^{\circ} \mathrm{C}$ with shaking at $200 \mathrm{rpm}$ for fermentation. After fermentation with various lengths, the concentration of polymyxin E was measured by HPLC and the gene expression was detected by quantitative real-time PCR (qRT-PCR).

2.2. Treatment of Precursor Amino Acids. To evaluate the effect of precursor amino acids on polymyxin E production and its biosynthesis-related genes expression, after $35 \mathrm{~h}$ fermentation, different precursor amino acids with various concentrations were added to culture for stimulation. After a further $8 \mathrm{~h}$ fermentation, the concentration of polymyxin $\mathrm{E}$ was measured by HPLC and the gene expression was analyzed by qRT-PCR.

2.3. HPLC Analysis of Polymyxin E. One milliliter of culture was centrifuged at $10,000 \mathrm{~g}$ for $10 \mathrm{~min}$ and the supernatant was collected after filtration with $0.45 \mu \mathrm{m}$ microporous membrane. Analysis was performed using an HPLC system (SHIMADZU, Japan). $20 \mu \mathrm{L}$ of supernatant sample was injected into a reverse-phase column, YMC Pack ODS-A $(150 \times 4.6 \mathrm{~mm}$ I.D., $5 \mu \mathrm{m})$, eluted at $33^{\circ} \mathrm{C}$, and analyzed in a mixed solvent of acetonitrile (22\%) and water containing $0.223 \% \mathrm{Na}_{2} \mathrm{SO}_{4}(78 \%)$, at a constant flow of $1 \mathrm{~mL} / \mathrm{min}$. Peak of polymyxin E was determined at wavelength of $240 \mathrm{~nm}$. Polymyxin E concentration produced by P. polymyxa was calculated based on the extracted correlation equation between the concentration of standard polymyxin $\mathrm{E}$ and the corresponding peak area in HPLC. One unit is equal to $0.0418 \mu \mathrm{g}$ of polymyxin E.

2.4. PCR Amplification and Sequence Collection of Genes Associated with Polymyxin E Biosynthesis. The partial sequences of $p m x A B C D E, s p o 0 A, a b r B$, ectB, and $s f p$ were amplified by PCR. The primers (Table 1) used for PCR were designed based on the complete genome sequence of Paenibacillus polymyxa E681 (GenBank number CP000154) [13]. The bacterial genomic DNA was extracted using a bacterial genomic DNA extraction kit (GE, USA). The gene fragments were amplified in $50 \mu \mathrm{L}$ containing $37 \mu \mathrm{L}$ of $\mathrm{ddH}_{2} \mathrm{O}, 5 \mu \mathrm{L}$ of $10 \mathrm{x}$ Easy Taq buffer, $4 \mu \mathrm{L}$ of $2.5 \mathrm{mM}$ dNTPs, $100 \mathrm{nM}$ forward primer, $100 \mathrm{nM}$ reverse primer, $1 \mathrm{ng}$ genomic DNA, and $1 \mathrm{U}$ Taq DNA polymerase (TaKaRa, Dalian, China) with denaturation at $94^{\circ} \mathrm{C}$ for $5 \mathrm{~min}$ followed by 30 cycles of $1 \mathrm{~min}$ at $94^{\circ} \mathrm{C}, 50 \mathrm{~s}$ at $55^{\circ} \mathrm{C}, 90 \mathrm{~s}$ at $72^{\circ} \mathrm{C}$, and a final $10 \mathrm{~min}$ extension at $72^{\circ} \mathrm{C}$. At the end of reaction, PCR product was cooled to $4^{\circ} \mathrm{C}$ for further use. After size confirmation on $1.0 \%$ agarose gel, the desired amplicons were purified using a gel extraction kit (Qiagen, CA, USA) for TA cloning with pMD19-T simple vector (TaKaRa, Dalian, China). After sequencing by Sangon Biotech (Shanghai, China), the gene sequences were collected and compared with the reference genes in GenBank for confirmation.

2.5. Analysis of Gene Expression Using qRT-PCR. To measure gene expression, qRT-PCR [28] was used to amplify cDNA products reversely transcribed from mRNA. In brief, the bacterial cell was harvested through centrifugation at 5,000 rpm for $5 \mathrm{~min}$ and the total RNA was extracted using an RNAiso Plus kit (Sangon, Shanghai, China). RNA integrity was determined based on the $\mathrm{OD}_{260 \mathrm{~nm}} / \mathrm{OD}_{280 \mathrm{~nm}}$ ratio $(>1.95)$, and $500 \mathrm{ng}$ of DNA-free RNA with high-quality was reversely transcribed to cDNA in a $10 \mu \mathrm{L}$ volume using PrimeScript RT Master Mix (Perfect Real Time) kit. After appropriate dilution, the cDNA was used for amplification of target gene fragment with primer sets (Table 2) by using the SYBR green Premix Ex Taq (Tli RNaseH Plus) kit. PCR was run on CFX Connect Real-Time System (Bio-Rad, Hercules, CA) with an amplification protocol consisting of an initial denaturation at $95^{\circ} \mathrm{C}$ for $10 \mathrm{~min}$, followed by 40 cycles of denaturation at $95^{\circ} \mathrm{C}$ for $15 \mathrm{~s}$ and annealing/elongation at $60^{\circ} \mathrm{C}$ for $30 \mathrm{~s}$. Immediately after the final PCR cycle, a melting-curve analysis was made to determine the reaction specificity based on the observed melting temperature from product. Unless otherwise specified, all the kits above were purchased from TaKaRa Bio. Inc. (Dalian, China).

The cycle threshold $\left(C_{T}\right)$ for each PCR was determined using StatView software which automatically sets the threshold signal at the log phase of amplification curve. Several 
TABLE 2: Sequences of primer pairs for real-time PCR analysis of gene expression.

\begin{tabular}{llcc}
\hline \multirow{2}{*}{ Genes } & \multicolumn{2}{c}{ Nucleotide sequences $\left(5^{\prime}-3^{\prime}\right)$} & Reverse primers \\
& TCAACTCGCTCAGAAGCGTT & TTGTACGGAAACCGACGGAG & Product sizes $(\mathrm{bp})$ \\
\hline$p m x A$ & ATGAAATCTTTGTTGAAAA & CCAGGACGTACACCCTCAAC & 105 \\
$p m x B$ & TATTCCCGAGCTCATCACGC & TCGGAAGCGAACGACCATTT & 111 \\
$p m x \mathrm{C} D$ & TGTTCGTTCAACGCCTCGTA & GCTTGCAAACGCTCGGTAAA & 107 \\
$p m x E$ & CACTTTGCCTGAAACGACCG & GCCAGAATGCGTTCATACCG & 118 \\
$s p o 0 A$ & TCGCAGAATCCCGCAACATA & CGGTTGTGGAGTCAGGTTCA & 111 \\
$a b r B$ & AAATACGGAACAGCCCGTCC & TCGCTCGCCTGTCTTCAAAT & 103 \\
$s f p$ & CAGTGGATACGGTCTGCCAA & CTCCGACAAACGCTAGCTGA & 114 \\
& GTACCTCCTGCGCAAAGTGA & CACGACAGAGGGCTTTACGA & 113 \\
\hline
\end{tabular}

dilutions of each cDNA sample were assayed for gene of interest in order to obtain a linear regression between the $C_{T}$ values (ranging from 20 to 35 cycles) and the log of cDNA. The amplification efficiency of gene was retrieved from the slope of that linear regression according to the formula $E=10^{(-1 / \text { slope })}$. The $116 \mathrm{bp}$ of housekeeping $16 \mathrm{~S}$ rRNA gene fragment was amplified by using primer set of 16SF ( $5^{\prime}$-GAGAAGAAAGCCCCGGCTAA- $\left.3^{\prime}\right)$ and 16SR $\left(5^{\prime}\right.$-ACCAGACTTAAAGAGCCGCC- $\left.3^{\prime}\right)$ and treated as the internal control to verify that there were equal amounts of target cDNA in all samples. The relative expression of the target gene compared to that of the reference $16 \mathrm{~S}$ rRNA gene was calculated by comparative $C_{T}$ method [29].

2.6. Data Analysis. All data were presented as mean \pm standard error and tested for statistical significance based on analysis of variance (ANOVA) followed by Dunnett's post hoc test using StatView 5.0 program. When the probability $(P)$ was less than 0.05 and 0.01 , the values were considered significantly and very significantly different, respectively.

\section{Results}

3.1. Accumulation of Polymyxin E during Fermentation. Polymyxin E produced by $P$. polymyxa was measured over a $96 \mathrm{~h}$ fermentation period using HPLC. As shown in Figure 2, no polymyxin E was detected within $35 \mathrm{~h}$. Then, its production rapidly increased from $35 \mathrm{~h}$ to $59 \mathrm{~h}$. Next, polymyxin E production kept almost constant in the remaining time frame. Thus, under these fermentation conditions, polymyxin $\mathrm{E}$ is mainly produced by $P$. polymyxa over a period from $35 \mathrm{~h}$ to $59 \mathrm{~h}$. Therefore, in the following experiments, a fermentation period from $35 \mathrm{~h}$ to $72 \mathrm{~h}$ was selected for monitoring polymyxin E production and the expression of genes involved in polymyxin E biosynthesis.

3.2. Expression of Genes Involved in Polymyxin E Biosynthesis. Figure 3(a) showed that the pmxA expression increased rapidly over a period from $35 \mathrm{~h}$ to $50 \mathrm{~h}$, in line with the increase of polymyxin E production. Then, $p m x A$ expression remained almost unchangeable till $72 \mathrm{~h}$, while polymyxin $\mathrm{E}$ production had a further increase from $50 \mathrm{~h}$ to $59 \mathrm{~h}$ and then

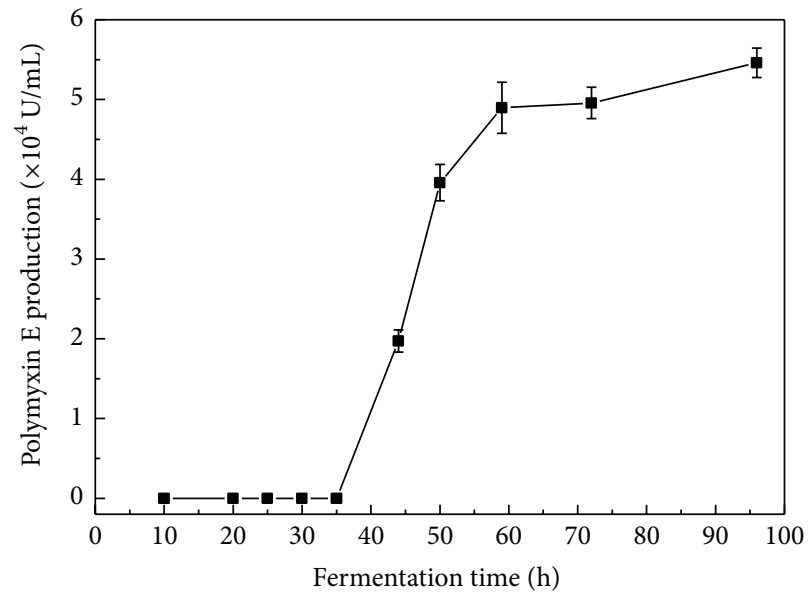

Figure 2: Polymyxin E accumulation in P. polymyxa during fermentation.

stayed constant. Over an entire $72 \mathrm{~h}$ fermentation period, the expression of another two polymyxin E synthetase genes, $p m x B$ and $p m x E$, as well as $p m x C$ and $p m x D$ genes kept increasing (Figures 3(a) and 3(b)). Similarly, the expression of both $e c t B$ and $s f p$ kept increasing (Figure $3(\mathrm{~d})$ ). The expression of $a b r B$, a negative regulator gene for $p m x A$, increased very slightly from $35 \mathrm{~h}$ to $45 \mathrm{~h}$, but rapidly from $45 \mathrm{~h}$ to $50 \mathrm{~h}$. After a further increase till $59 \mathrm{~h}$, its expression turned to decrease (Figure 3(c)). The expression of spo0A, another important regulator gene for $a b r B$, also increased very slightly from $35 \mathrm{~h}$ to $45 \mathrm{~h}$ and rapidly from $35 \mathrm{~h}$ to $50 \mathrm{~h}$, but its expression turned to decrease at $50 \mathrm{~h}$ (Figure 3(c)). Therefore, there exists a delay in the change pattern between $a b r B$ expression and spo0A expression. Most probably, Spo0A needs phosphorylation before negative regulation on $a b r B$ expression [21,22]. All these results indicated that polymyxin $\mathrm{E}$ biosynthesis is probably limited due to the repression of pmxA expression, which has probably resulted from AbrB accumulation, consistent with the reports [20-23].

3.3. Repression of Polymyxin E Production by Precursor Amino Acids. Polymyxin E requires precursor amino acids including L-Dab, L-Leu, D-Leu, and L-Thr for its biosynthesis. 


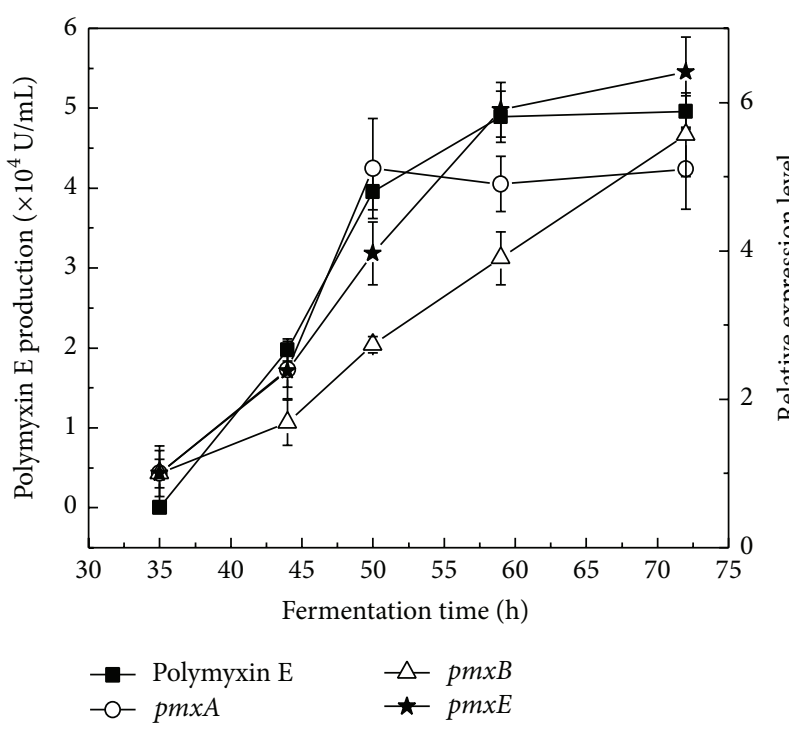

(a)

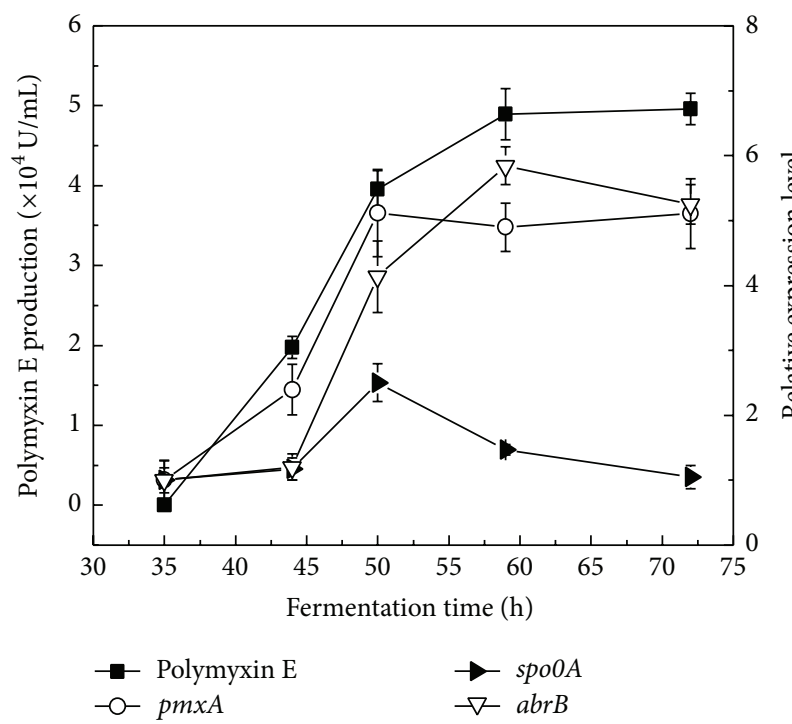

(c)

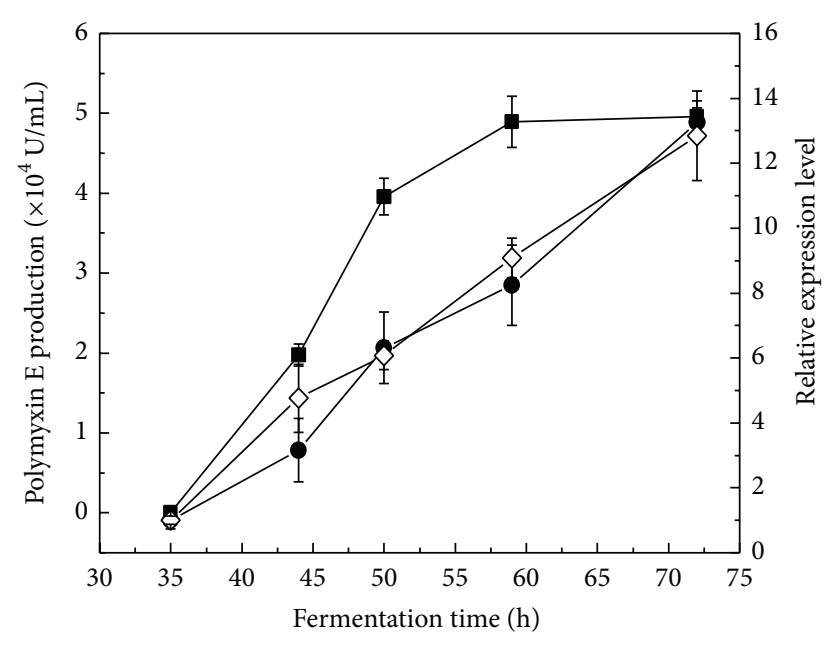

$\rightarrow$ Polymyxin E $\prec p m x D$

$p m x C$

(b)

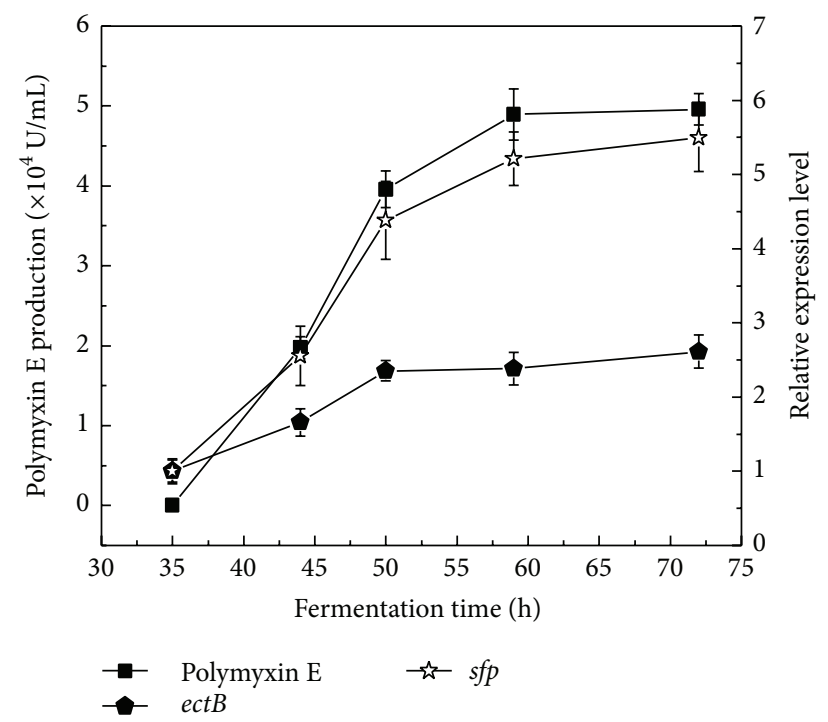

(d)

FIGURE 3: Polymyxin E accumulation and relative expression of genes including $p m x A, p m x B$, and $p m x E$ (a), $p m x C$ and $p m x D$ (b), $p m x A$, $s p o 0 A$, and $a b r B(\mathrm{c})$, and $e c t B$ and $s f p(\mathrm{~d})$.

Figure 4 showed that, compared to control without addition of precursor amino acids, the treatments with precursor amino acids at low concentration $(0.05 \mathrm{mmol} / \mathrm{L})$ all had no significant effect on polymyxin E production. However, addition of precursor amino acids to higher concentration repressed the polymyxin E production. In general, the higher the concentration of precursor amino acids from $0.5 \mathrm{mmol} / \mathrm{L}$ to $5 \mathrm{mmol} / \mathrm{L}$, the stronger the repression to polymyxin $\mathrm{E}$ production. L-Dab at $0.5 \mathrm{mmol} / \mathrm{L}$ significantly $(P<0.05)$ decreased polymyxin E production. Similarly, L-Leu and $\mathrm{D}$-Leu at $0.5 \mathrm{mmol} / \mathrm{L}$ as well as L-Thr, L-Leu, and D-Leu at $5 \mathrm{mmol} / \mathrm{L}$ all very significantly $(P<0.01)$ suppressed polymyxin E production.
3.4. Regulation of Precursor Amino Acids on the Expression of Genes Involved in Polymyxin E Biosynthesis. L-Dab is biosynthesized by EctB in cells [30]. As shown in Figure 5(a), $\mathrm{L}-\mathrm{Dab}$ at $0.05 \mathrm{mmol} / \mathrm{L}$ had no significant impact on ectB expression, while the ones at both $0.5 \mathrm{mmol} / \mathrm{L}$ and $5 \mathrm{mmol} / \mathrm{L}$ significantly $(P<0.05)$ and very significantly $(P<0.01)$ downregulated the ectB expression, respectively. In addition, as substrate of both PmxA and PmxE, L-Dab at $5 \mathrm{mmol} / \mathrm{L}$ significantly reduced their coding genes expression. On the contrary, other genes' expression was almost unaffected by LDab.

Both L-Leu and D-Leu are substrate amino acids of PmxA for polymyxin $\mathrm{E}$ biosynthesis. It was shown that L-Leu at 

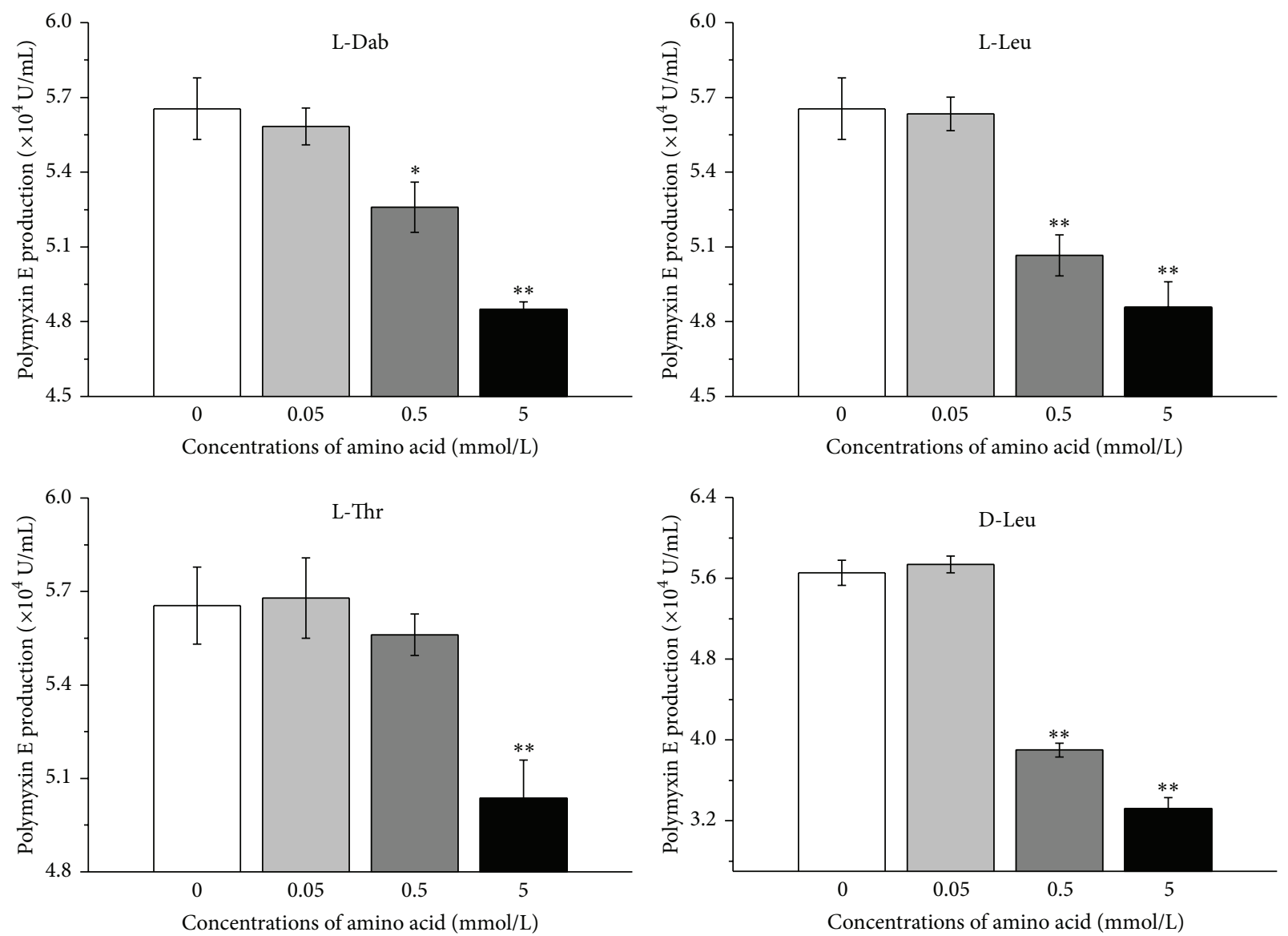

FIGURE 4: Effect of precursor amino acids on polymyxin E production. “*” and “**” represent a statistically significant $(P<0.05)$ and very significant $(P<0.01)$ difference, respectively, when compared to the control without addition of precursor amino acid at $35 \mathrm{~h}$.

$0.5 \mathrm{mmol} / \mathrm{L}$ and $5 \mathrm{mmol} / \mathrm{L}$ significantly $(P<0.05)$ and very significantly $(P<0.01)$ repressed the $p m x A$ expression, respectively. Similarly, D-Leu at $0.5 \mathrm{mmol} / \mathrm{L}$ and $5 \mathrm{mmol} / \mathrm{L}$ both significantly $(P<0.05)$ reduced the $p m x A$ expression. However, they had no significant impact on other genes' expression (Figures 5(b) and 5(c)).

Interestingly, as substrate amino acid of both $\mathrm{PmxB}$ and PmxE, L-Thr had no significant effect on either $p m x B$ or $p m x E$ expression (Figure 5(d)) but surprisingly affected the expression of $a b r B, s p o 0 A$, and $p m x A$. L-Thr at $0.5 \mathrm{mmol} / \mathrm{L}$ caused significant $(P<0.05)$ increase in $a b r B$ expression. Moreover, L-Thr at $5 \mathrm{mmol} / \mathrm{L}$ significantly $(P<0.05)$ and very significantly $(P<0.01)$ downregulated the expression of $p m x A$ and $s p o 0 A$, respectively, and very significantly $(P<$ $0.01)$ upregulated the $a b r B$ expression.

3.5. Effect of Indirect-Precursor Amino Acid on Polymyxin E Production and the Expression of Genes Involved in Polymyxin E Synthesis. L-Dab is biosynthesized from L-Asp in cells. Therefore, L-Asp was chosen as an indirect-precursor amino acid in polymyxin E biosynthesis. As shown in Figure 6(a), L-Asp at $5 \mathrm{mmol} / \mathrm{L}$ also significantly $(P<0.05)$ decreased the polymyxin E production. Data in Figure 6(b) further showed that L-Asp at $5 \mathrm{mmol} / \mathrm{L}$ significantly $(P<0.05)$ repressed the expression of $p m x A, p m x E$, spo0A, and $e c t B$ and very significantly $(P<0.01)$ stimulated the $a b r B$ expression.

3.6. Effect of Nonprecursor Amino Acid on Polymyxin E Production and the Expression of Genes Involved in Polymyxin $E$ Biosynthesis. L-Phe was chosen as a representative of nonprecursor amino acids for polymyxin E biosynthesis. As shown in Figure 7, $5 \mathrm{mmol} / \mathrm{L}$ of L-Phe had no significant influence on both polymyxin $\mathrm{E}$ accumulation and the expression of polymyxin E biosynthesis-associated genes.

\section{Discussion}

It has been reported that $\mathrm{AbrB}$ repressed the expression of $t y c A$ encoding tyrocidine synthetase I, an enzyme for cyclic decapeptide tyrocidine biosynthesis in Bacillus brevis [23]. Another report showed that $a b r B$ deletion strongly increased lantibiotic subtilin production in Bacillus subtilis [31]. Recently, AbrB was found to directly bind to the upstream region of $p m x A$ for negative regulation on polymyxin biosynthesis [20]. It was believed that negative regulation function of $\mathrm{AbrB}$ is probably due to its direct binding to promoter of the genes [20]. Spo0A also functions as a regulator of many genes through repression of $a b r B$ 

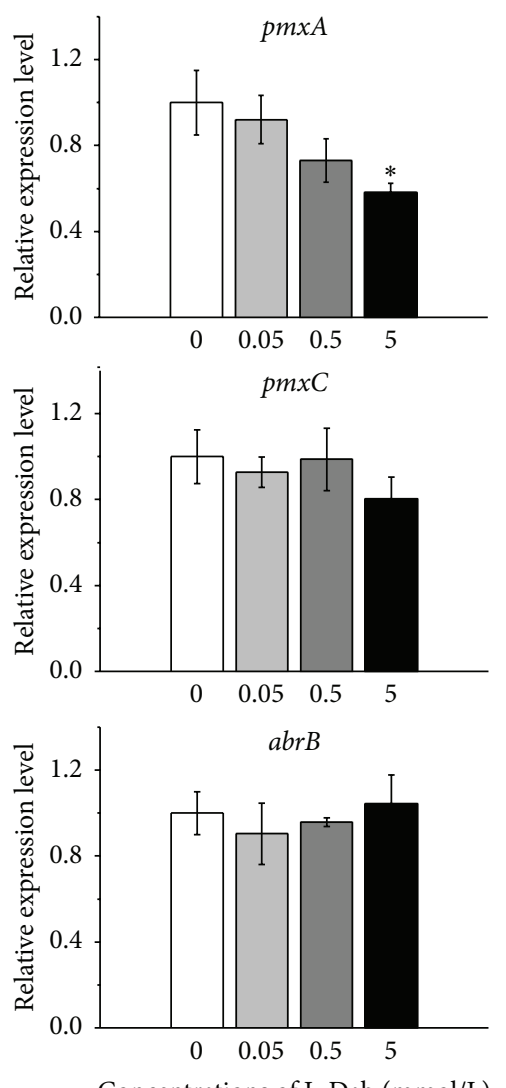

Concentrations of L-Dab $(\mathrm{mmol} / \mathrm{L})$
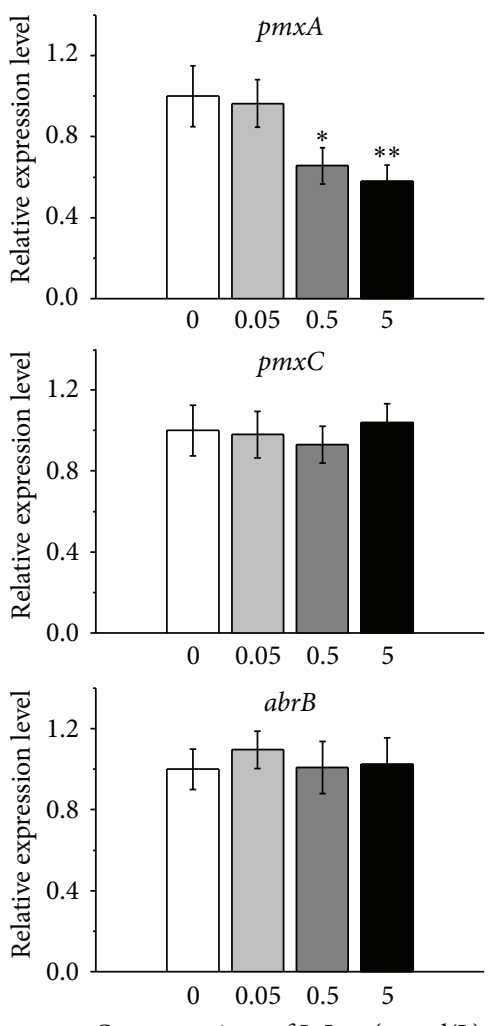

Concentrations of L-Leu $(\mathrm{mmol} / \mathrm{L})$
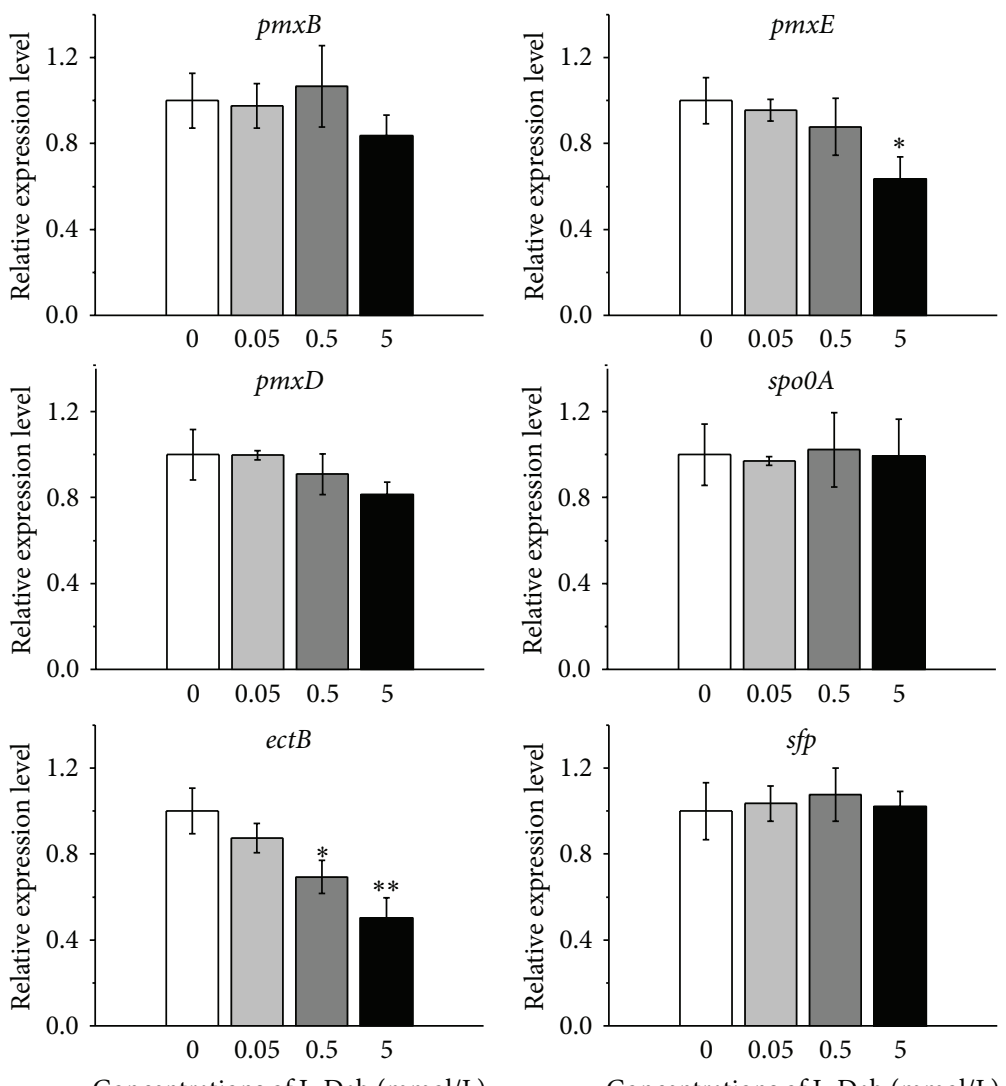

(a)
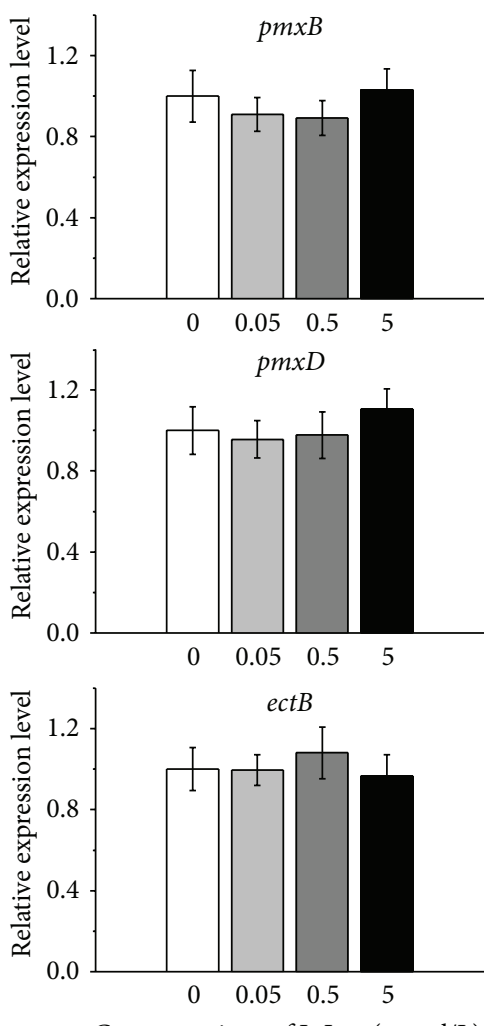

(b)
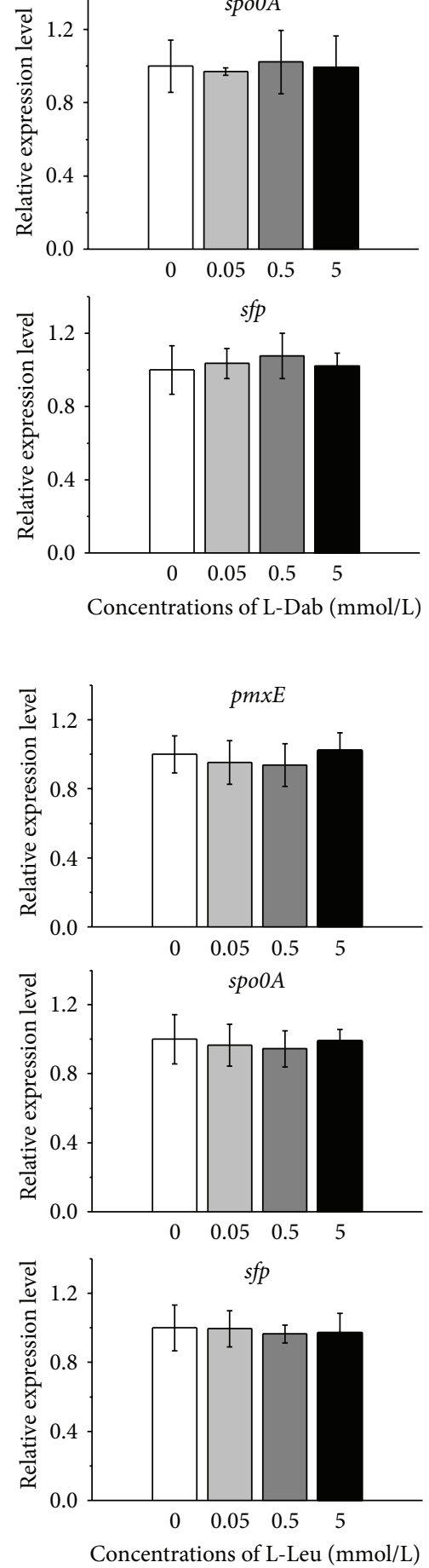

Concentrations of L-Dab ( $\mathrm{mmol} / \mathrm{L})$

FIgure 5: Continued. 

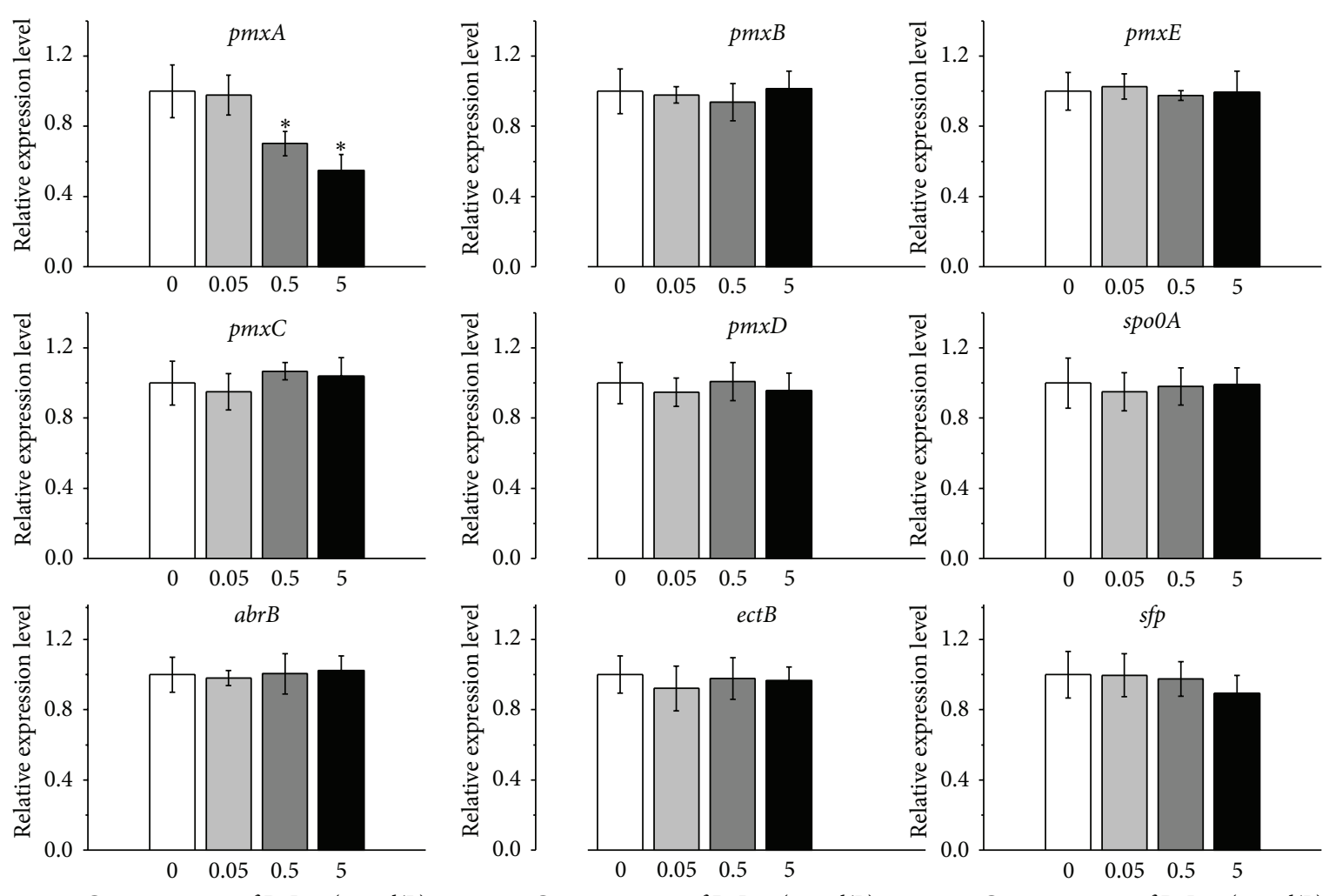

Concentrations of D-Leu $(\mathrm{mmol} / \mathrm{L})$

Concentrations of D-Leu $(\mathrm{mmol} / \mathrm{L})$

(c)
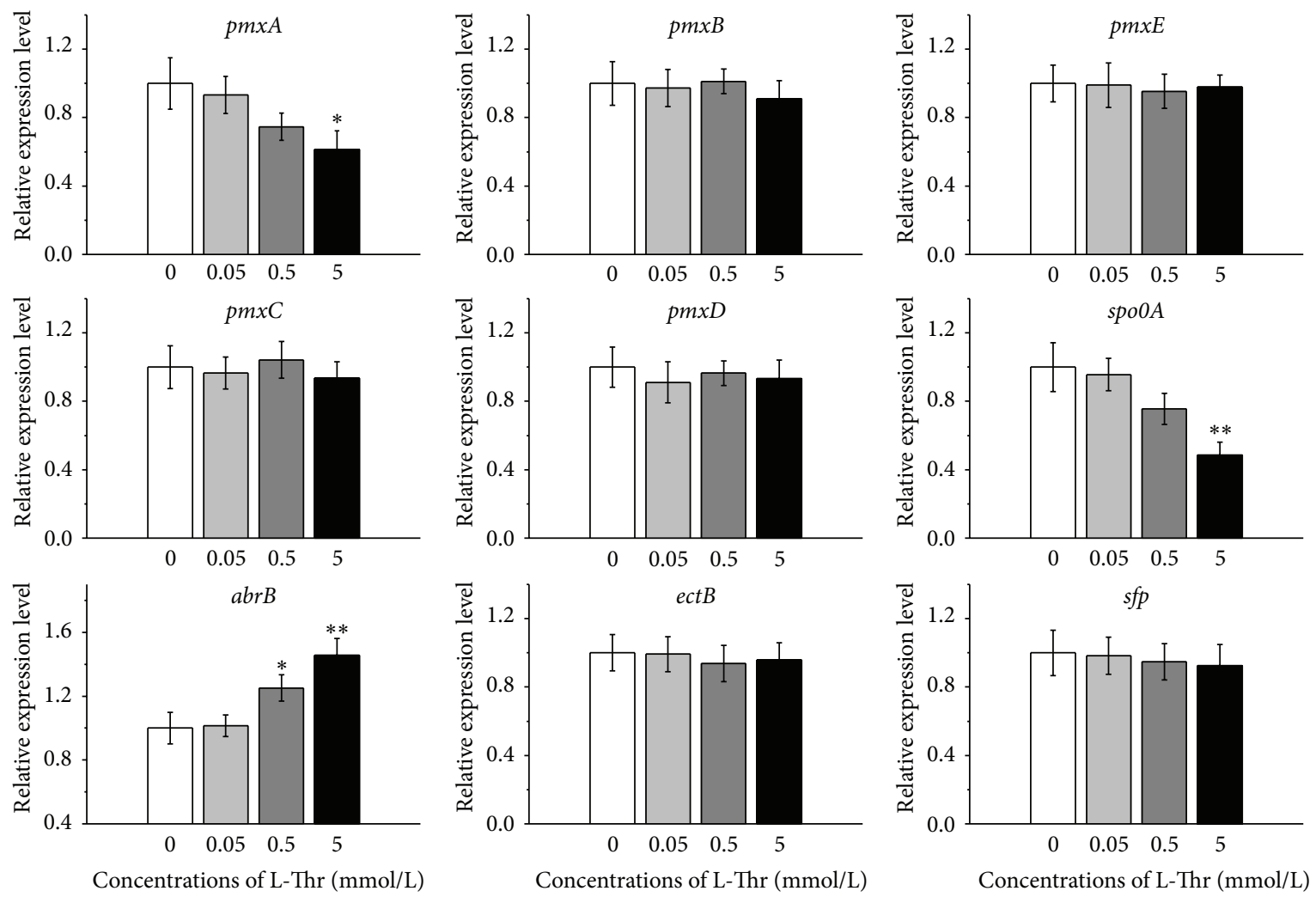

(d)

Figure 5: Effect of precursor amino acids on the expression of genes involved in polymyxin E synthesis. (a) L-Dab; (b) L-Leu; (c) D-Leu; and (d) L-Thr. 


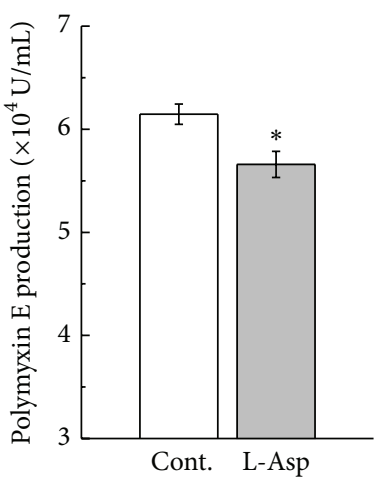

(a)

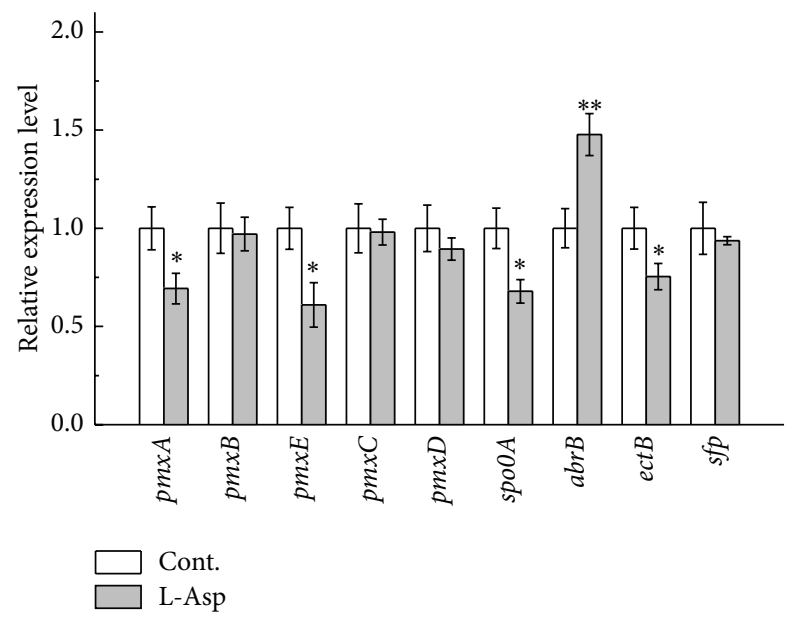

(b)

FIGURE 6: Effect of L-Asp on polymyxin E production (a) and the expression of genes involved in polymyxin E biosynthesis (b). Cont.: control group (fermentation without L-Asp addition).

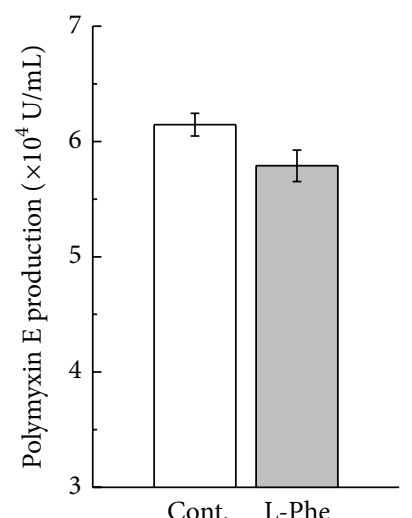

(a)

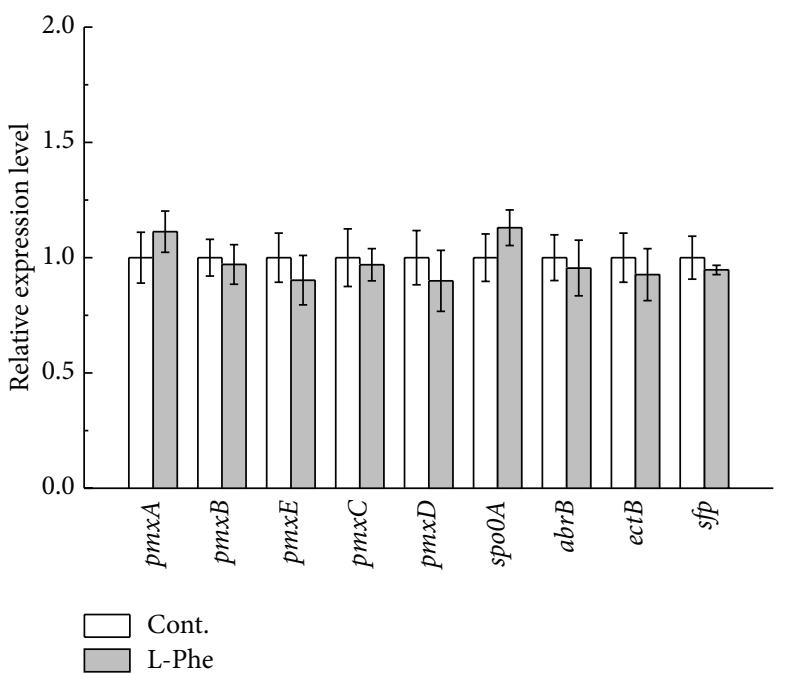

(b)

FIGURE 7: Effect of nonprecursor amino acid of L-Phe on polymyxin E production (a) and the expression of genes involved in polymyxin E biosynthesis (b). Cont.: control group (fermentation without L-Phe addition).

expression [21, 22]. In Bacillus cereus, cereulide production was regulated by Spo0A and AbrB through controlling the expression of its biosynthesis gene [30]. Our study showed that the expression of genes $p m x A, a b r B$, and spo0A together with polymyxin E production in P. polymyxa all increased from $35 \mathrm{~h}$ to $50 \mathrm{~h}$. The spo0A expression would result in Spo0A accumulation which probably suppressed the $a b r B$ expression at $59 \mathrm{~h}$. Spo0A needs phosphorylation before negative regulation on $a b r B$ expression [21, 22], explaining the delay in the change pattern between the $a b r B$ and spooA expression. Similarly, the $a b r B$ expression from $35 \mathrm{~h}$ to $50 \mathrm{~h}$ may cause AbrB accumulation to a certain concentration level which subsequently repressed the pmxA expression at $50 \mathrm{~h}$ probably by directly binding to upstream region of $p m x A$ [18]. This led to suppression of polymyxin E biosynthesis at $59 \mathrm{~h}$.
Polymyxin E is a secondary metabolite, which is supported by our result that it accumulated mainly over a period from $35 \mathrm{~h}$ to $59 \mathrm{~h}$ (Figure 2). Though addition of either Dab or its precursor L-Asp to medium at the beginning of fermentation has been shown to stimulate polymyxin E production [19], our results showed that, after $35 \mathrm{~h}$ fermentation, the addition of precursor amino acids to high concentration all repressed polymyxin E production (Figure 4). There are several possible explanations for this inconsistency. Most probably, the fermentation medium for addition of precursor amino acids, addition moment of precursor amino acids, the used producer strain, and/or concentration of precursor amino acids are different between the two cases. The mimic experiment by using the same condition [19] besides strain further showed that L-Dab addition to medium M [19] 
also caused a reduced polymyxin E production (data not shown). Therefore, this discrepancy most probably attributes to the difference of the used strain. As substrate amino acids of PmxA, L-Dab, L-Leu, and D-Leu significantly repressed the pmxA expression. Similarly, as substrate amino acid of PmxE, L-Dab had significant repression on $p m x E$ expression. However, L-Thr, the substrate amino acid of both $\mathrm{PmxB}$ and PmxE, significantly affected the expression of regulation genes $s p o 0 A$ and $a b r B$, instead of $p m x B$ and $p m x E$. Most probably, L-Thr suppressed the spo0A expression and stimulated the $a b r B$ expression, eventually leading to the repression of pmxA expression. Accordingly, polymyxin E production was inhibited. Polymyxin E includes 6 L-Dabs synthesized by EctB $[32,33]$. Our data indicated that the ectB expression decreased after addition of L-Dab to $5 \mathrm{mmol} / \mathrm{L}$, suggesting that L-Dab at high concentration can downregulate the ectB expression. L-Dab is biosynthesized from L-Asp. It was found that L-Asp also affected the ectB expression. Interestingly, L-Asp repressed the expression of both $p m x A$ and $p m x E$. Moreover, L-Asp increased and decreased the expression of spo0A and $a b r B$, respectively. Most probably, L-Asp addition will enhance the L-Dab concentration in cells, accordingly affecting the L-Dab-associated genes expression. In contrast, all the precursor amino acids unaffected the expression of $p m x C$ and $p m x D$ as well as $s f p$.

To our best knowledge, it is the first time to investigate the effect of precursor amino acids on polymyxin E production and its biosynthesis-associated genes expression. This is helpful for understanding the regulation mechanism for polymyxin $\mathrm{E}$ biosynthesis during fermentation.

\section{Conflict of Interests}

The authors have declared that no conflict of interests exists.

\section{Authors' Contribution}

Zhiliang Yu and Juanping Qiu contributed equally to this work.

\section{Acknowledgment}

This work was supported by the Regional Demonstration of Marine Economy Innovative Development Project, China (no. 12PYY001SF08).

\section{References}

[1] D. R. Storm, K. S. Rosenthal, and P. E. Swanson, "Polymyxin and related peptide antibiotics," Annual Review of Biochemistry, vol. 46, pp. 723-763, 1977.

[2] A. P. Zavascki, L. Z. Goldani, J. Li, and R. L. Nation, "Polymyxin $B$ for the treatment of multidrug-resistant pathogens: a critical review," Journal of Antimicrobial Chemotherapy, vol. 60, no. 6, pp. 1206-1215, 2007.

[3] M. N. Alekshun and S. B. Levy, "Molecular mechanisms of antibacterial multidrug resistance," Cell, vol. 128, no. 6, pp.10371050, 2007.
[4] T. Gumbo, "Biological variability and the emergence of multidrug-resistant tuberculosis," Nature Genetics, vol. 45, no. 7, pp. 720-721, 2013.

[5] D. J. Payne, M. N. Gwynn, D. J. Holmes, and D. L. Pompliano, "Drugs for bad bugs: confronting the challenges of antibacterial discovery," Nature Reviews Drug Discovery, vol. 6, no. 1, pp. 2940, 2007.

[6] J. Li, R. L. Nation, J. D. Turnidge et al., "Colistin: the reemerging antibiotic for multidrug-resistant Gram-negative bacterial infections," The Lancet Infectious Diseases, vol. 6, no. 9, pp. 589-601, 2006.

[7] M. E. Falagas and A. Michalopoulos, "Polymyxins: old antibiotics are back," The Lancet, vol. 367, no. 9511, pp. 633-634, 2006.

[8] H. Tsubery, I. Ofek, S. Cohen, M. Eisenstein, and M. Fridkin, "Modulation of the hydrophobic domain of polymyxin B nonapeptide: Effect on outer-membrane permeabilization and lipopolysaccharide neutralization," Molecular Pharmacology, vol. 62, no. 5, pp. 1036-1042, 2002.

[9] N. I. Martin, H. Hu, M. M. Moake et al., "Isolation, structural characterization, and properties of mattacin (polymyxin M), a cyclic peptide antibiotic produced by Paenibacillus kobensis M," The Journal of Biological Chemistry, vol. 278, no. 15, pp. 1312413132, 2003.

[10] S. Komura and K. Kurahashi, "Biosynthesis of polymyxin E. III. total synthesis of polymyxin E by a cell-free enzyme system," Biochemical and Biophysical Research Communications, vol. 95, no. 3, pp. 1145-1151, 1980.

[11] D. Schwarzer, R. Finking, and M. A. Marahiel, "Nonribosomal peptides: from genes to products," Natural Product Reports, vol. 20, no. 3, pp. 275-287, 2003.

[12] M. Shaheen, J. Li, A. C. Ross, J. C. Vederas, and S. E. Jensen, "Paenibacillus polymyxa PKB1 produces variants of polymyxin B-type antibiotics," Chemistry \& Biology, vol. 18, no. 12, pp. 1640-1648, 2011.

[13] J. F. Kim, H. Jeong, S.-Y. Park et al., "Genome sequence of the polymyxin-producing plant-probiotic rhizobacterium Paenibacillus polymyxa E681," Journal of Bacteriology, vol. 192, no. 22, pp. 6103-6104, 2010.

[14] M. Mingchao, C. Wang, Y. Ding et al., "Complete genome sequence of Paenibacillus polymyxa SC2, a strain of plant growth-promoting rhizobacterium with broad-spectrum antimicrobial activity," Journal of Bacteriology, vol. 193, no. 1, pp. 311-312, 2011.

[15] B. Niu, C. Rueckert, J. Blom, Q. Wang, and R. Borriss, “The genome of the plant growth-promoting rhizobacterium Paenibacillus polymyxa M-1 contains nine sites dedicated to nonribosomal synthesis of lipopeptides and polyketides," Journal of Bacteriology, vol. 193, no. 20, pp. 5862-5863, 2011.

[16] A. W. Eastman, B. Weselowski, N. Nathoo, and Z. C. Yuan, "Complete genome sequence of Paenibacillus polymyxa CR1, a plant growth-promoting bacterium isolated from the corn rhizosphere exhibiting potential for biocontrol, biomass degradation, and biofuel production," Genome Announcements, vol. 2, pp. 1-2, 2014.

[17] S.-K. Choi, S.-Y. Park, R. Kim et al., "Identification of a polymyxin synthetase gene cluster of Paenibacillus polymyxa and heterologous expression of the gene in Bacillus subtilis," Journal of Bacteriology, vol. 191, no. 10, pp. 3350-3358, 2009.

[18] S.-Y. Park, S.-K. Choi, J. Kim, T.-K. Oh, and S.-H. Park, "Efficient production of polymyxin in the surrogate host Bacillus subtilis by introducing a foreign $e c t B$ gene and disrupting the $a b r B$ 
gene," Applied and Environmental Microbiology, vol. 78, no. 12, pp. 4194-4199, 2012.

[19] Y. Kuratsu, Y. Arai, K. Inuzuka, and T. Suzuki, "Stimulatory effect of aspartic acid on colistin production by Bacillus polymyxa," Agricultural and Biological Chemistry, vol. 47, no. 11, pp. 2607-2612, 1983.

[20] M. Fujita, J. E. González-Pastor, and R. Losick, "High- and low-threshold genes in the Spo0A regulon of Bacillus subtilis," Journal of Bacteriology, vol. 187, no. 4, pp. 1357-1368, 2005.

[21] V. Molle, M. Fujita, S. T. Jensen et al., "The Spo0A regulon of Bacillus subtilis," Molecular Microbiology, vol. 50, no. 5, pp.16831701, 2003.

[22] M. Perego, G. B. Spiegelman, and J. A. Hoch, "Structure of the gene for the transition state regulator, abrB: regulator synthesis is controlled by the spo0A sporulation gene in Bacillus subtilis," Molecular Microbiology, vol. 2, no. 6, pp. 689-699, 1988.

[23] J. B. Robertson, M. Gocht, M. A. Marahiel, and P. Zuber, "AbrB, a regulator of gene expression in Bacillus, interacts with the transcription initiation regions of a sporulation gene and an antibiotic biosynthesis gene," Proceedings of the National Academy of Sciences of the United States of America, vol. 86, no. 21, pp. 8457-8461, 1989.

[24] L. E. N. Quadri, P. H. Weinreb, M. Lei, M. M. Nakano, P. Zuber, and C. T. Walsh, "Characterization of Sfp, a Bacillus subtilis phosphopantetheinyl transferase for peptidyl carder protein domains in peptide synthetases," Biochemistry, vol. 37, no. 6, pp. 1585-1595, 1998.

[25] T. L. Foley and M. D. Burkart, "A homogeneous resonance energy transfer assay for phosphopantetheinyl transferase," Analytical Biochemistry, vol. 394, no. 1, pp. 39-47, 2009.

[26] M. Sunbul, N. J. Marshall, Y. Zou, K. Zhang, and J. Yin, "Catalytic turnover-based phage selection for engineering the substrate specificity of Sfp phosphopantetheinyl transferase," Journal of Molecular Biology, vol. 387, no. 4, pp. 883-898, 2009.

[27] Z. Yu, W. Qin, J. Lin, S. Fang, and J. Qiu, "Antibacterial mechanisms of polymyxin and bacterial resistance," BioMed Research International, vol. 2015, Article ID 679109, 11 pages, 2015.

[28] M. W. Pfaffl, "A new mathematical model for relative quantification in real-time RT-PCR," Nucleic Acids Research, vol. 29, no. 9, p. e45, 2001.

[29] T. D. Schmittgen and K. J. Livak, "Analyzing real-time PCR data by the comparative $C_{T}$ method," Nature Protocols, vol. 3, no. 6 , pp. 1101-1108, 2008.

[30] G. Lücking, M. K. Dommel, S. Scherer, A. Fouot, and M. Ehling-Schulz, "Cereulide synthesis in emetic Bacillus cereus is controlled by the transition state regulator AbrB, but not by the virulence regulator PlcR," Microbiology, vol. 155, no. 3, pp. $922-$ 931, 2009.

[31] T. Stein, S. Borchert, P. Kiesau et al., "Dual control of subtilin biosynthesis and immunity in Bacillus subtilis," Molecular Microbiology, vol. 44, no. 2, pp. 403-416, 2002.

[32] A. S. Reshetnikov, V. N. Khmelenina, I. I. Mustakhimov, and Y. A. Trotsenko, "Genes and enzymes of Ectoine biosynthesis in halotolerant methanotrophs," Methods in Enzymology, vol. 495, pp. 15-30, 2011.

[33] S. H. Saum and V. Müller, "Growth phase-dependent switch in osmolyte strategy in a moderate halophile: ectoine is a minor osmolyte but major stationary phase solute in Halobacillus halophilus," Environmental Microbiology, vol. 10, no. 3, pp. 716726, 2008. 

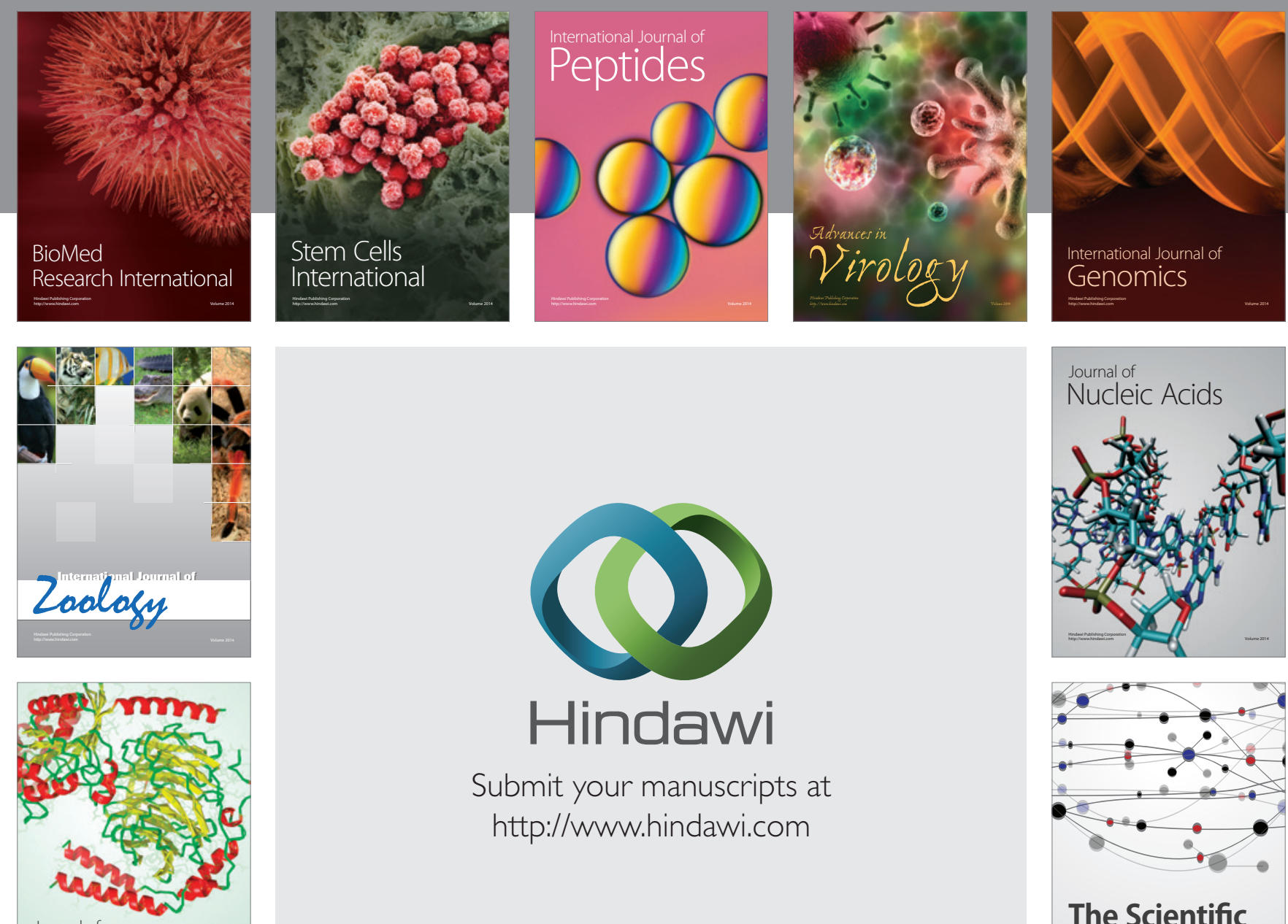

Submit your manuscripts at

http://www.hindawi.com

Journal of
Signal Transduction
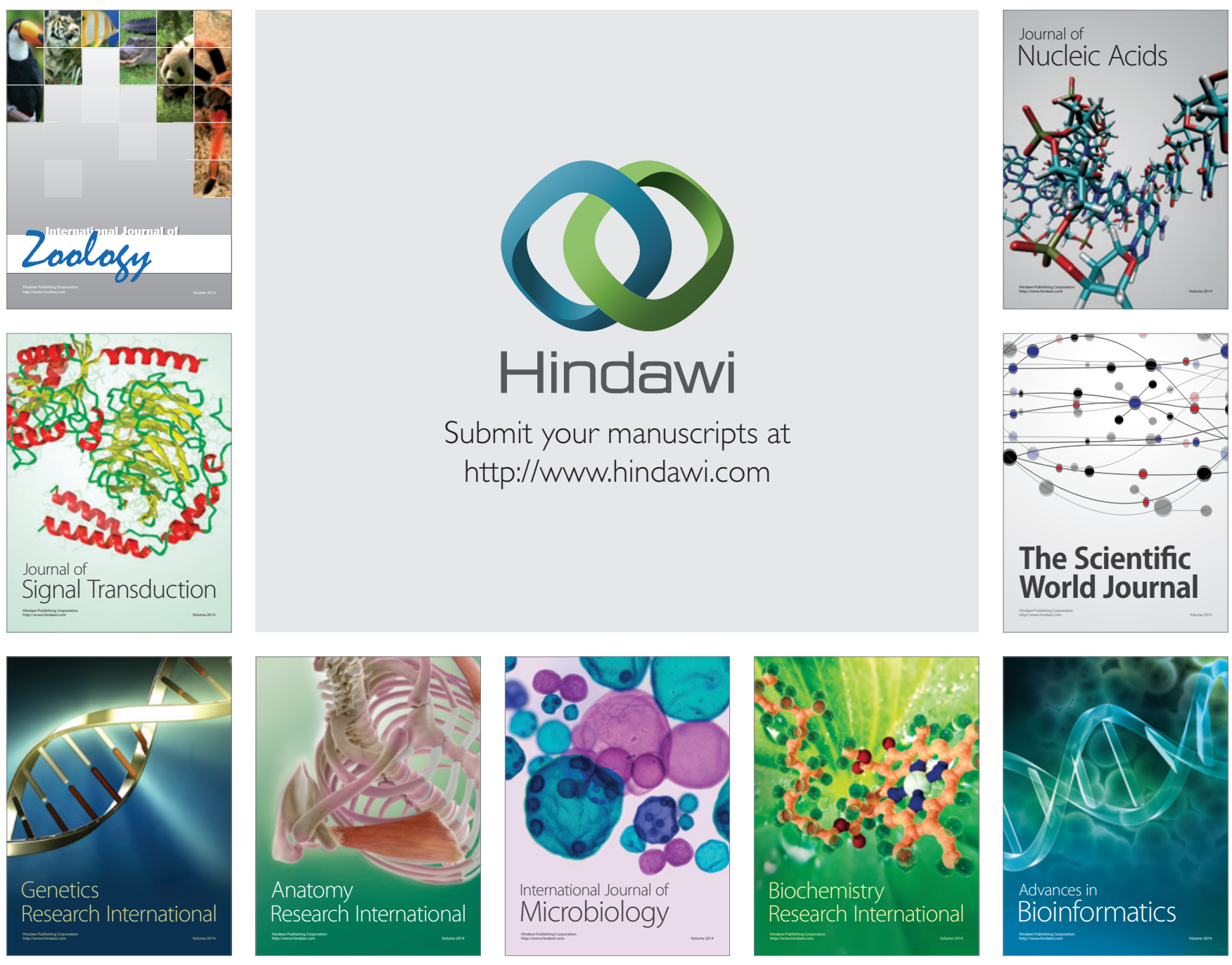

The Scientific World Journal
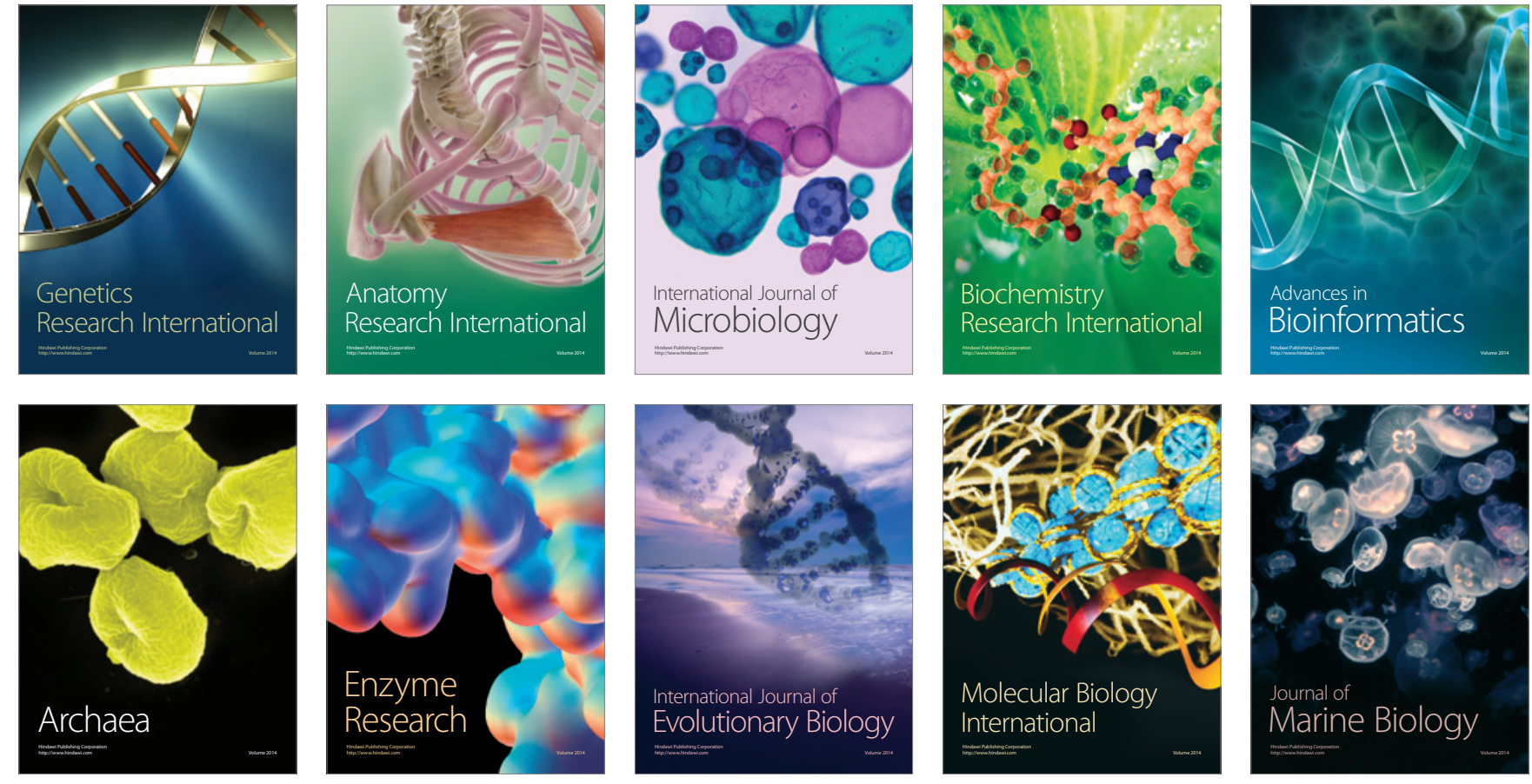